\title{
PENGARUH PENDEKATAN CONTEXTUAL TEACHING AND LEARNING (CTL) TERHADAP HASIL BELAJAR MATEMATIKA
}

\author{
Nuril Hidayati \\ (SMP Negeri 4 Waru) \\ nurilhidayati1289@yahoo.com
}

\begin{abstract}
Students often have difficulty in linking the material with the problems of life in the real world. This may result in a decrease in mathematics learning outcomes in schools. Therefore, teachers should be able to make learning fun during the learning process. To overcome these problems, teachers can use the approach Contextual Teaching and Learning (CTL) during learning process. This contextual approach to make students more active and to encourage students to make connections between knowledge and real-life situation. The purpose of this study was to determine whether there is influence approach Contextual Teaching and Learning (CTL) on learning outcomes mathematics SMP Negeri 4 Waru Academic Year 2015-2016. During the learning activities, the experimental class students formed into groups. Each group consisted of 4-5 students. During the learning process, the researchers fed the material set in the experimental class and the control class as samples in the study. Researchers chose the material set for the number of students who have difficulty in solving the problem set. To obtain the data result of learning mathematics, researchers took data from the pre-test and post-test. Pre-test given to students to find out how the students' abilities before receiving material taught by researchers, while the post-test was given to determine student learning outcomes after the student has finished the learning activities. Both of these classes have the same number of students is 32 students. In this study, found that $T_{\text {value }}=2.21>T_{\text {table }}=1,999$ with $\alpha=5 \%$ and $d k=62$. From these results it $H_{o}$ is rejected and Ha is it can be concluded that there is influence approach Contextual Teaching and Learning (CTL) on learning outcomes mathematics SMP Negeri 4 Waru Academic Year 2015-2016.
\end{abstract}

Keywords: CTL (Contextual Teaching and Learning), sudent's achievement.

\section{PENDAHULUAN}

Banyak siswa yang menganggap pelajaran matematika itu sangat sulit. Kesulitan yang dialami siswa merupakan akibat dari kurang pemahaman siswa terhadap materi yang diajarkan oleh guru di kelas. Dalam konteks nyata, siswa seringkali mengalami kesulitan dalam mengaitkan materi dengan masalah kehidupan di dunia nyata. Hal ini dapat mengakibatkan terjadinya penurunan hasil belajar matematika di sekolah. Untuk mengatasi masalah tersebut, peneliti memilih pembelajaran dengan pendekatan Contextual Teaching and Learning (CTL) sebagai pendekatan pembelajaranketika kegiatan belajar mengajar. Pendekatan kontekstual ini menjadikan siswa tidak pasif dalam merespon apa yang dijelaskan oleh guru. Menurut Trianto (2007:102) pengajaran kontekstual adalah pengajaran yang memungkinkan siswa-siswi TK sampai dengan SMU untuk menguatkan, memperluas, dan menerapkan pengetahuan dan keterampilan akademik mereka dalam berbagai macam tatanan dalam sekolah dan luar sekolah agar dapat memecahkan masalah- masalah dunia nyata atau masalah-masalah yang disimulasikan.

Pendekatan kontekstual dapat dikatakan sebagai pendekatan secara alamiah, karena konsep dari pembelajaran tersebut mengaitkan dengan kehidupan sehari-hari dalam dunia nyata. Dengan mengaitkan hubungan di dalam kelas dan di luar kelas, dapat menjadikan pengalaman bagi siswa yang menyenangkan dan dapat membangun pengetahuan yang mereka terapkan di luar kelas. Dengan menerapkan pendekatan kontekstual, siswa dapat menyelesaikan masalah dalam kehidupan sehari-hari misalkan di rumah, pasar, maupun di tempat lain.

Pendekatan kontekstual ini memberikan arti dan manfaat yang berarti khususnya bagi siswa,diantaranya dapat meningkatkan motivasi belajar siswa dalam memecahkan masalah dalam kehidupan sehari-hari serta mendapat pengalaman belajar yang bermanfaat yang dapat 
digunakan untuk menyelesaikan permasalahan yang dihadapi. Pembelajaran yang menyenangkan dapat membantu siswa untuk meningkatkan hasil belajar siswa.Orang tua selalu menginginkan anaknya untuk memperoleh hasil belajar yang baik di dalam kelas.Klasifikasi hasil belajar dari Benyamin Bloom yang secara garis besar membaginya menjadi tiga ranah, yakni ranah kognitif, ranah efektif, dan ranah psikomotor (Sudjana, 2011:23). Pendekatan kontekstual dianggap menyenangkan karena siswa dapat menerapkan dalam kehidupan sehari-sehari.Siswa tidak hanya memecahkan masalah pada materi yang diajarkan tetapi juga dapat memecahkan masalah di luar kelas.

Berdasarkan masalah di atas, peneliti mencoba memecahkan masalah tersebut untuk meningkatkan hasil belajar siswa terutama pada mata pelajaran matematika.Berdasarkan uraian di atas, penelitian ini igin menjawab permasalahan, adakah pengaruh pendekatan Contextual Teaching and Learning (CTL) terhadap hasil belajar matematika SMP Negeri 4 Waru tahun ajaran 20152016? yang hasilnya diharapkan dapat bermanfaat khususnya bagi guru matematika sebagai bahan referensi dalam upaya meningkatkan hasil belajar siswa khusunya matematika. Dengan demikian, penelitian ini bertujuan untuk mengetahui ada tidaknya pengaruh pendekatan Contextual Teaching and Learning (CTL) terhadap hasil belajar matematika SMP Negeri 4 Waru tahun ajaran 20152016.

\section{METODE PENELITIAN}

Penelitian ini merupakan penelitian PreExperimental dengan rancanganOne GroupPretestPosttest (Sugiyono,2013:109) yang bertujuan untuk mengetahui pengaruh pendekatan Contextual Teaching and Learning (CTL) terhadap hasil belajar matematika pada siswa SMP. Dalam penelitian ini, populasinya adalah semua siswa kelas VII SMP Negeri 4 Waru tahun ajaran 2015-2016, sedangkan sampelnya adalah siswa kelas VII6 dan kelas VII-7 SMP Negeri 4 Waru tahun ajaran 20152016. Selama proses pembelajaran kelas VII-6 sebagai kelas kontrol menggunakan pembelajaran langsung, sedangkan kelas VII-7 sebagai kelas eksperimen menggunakan pendekatan Contextual Teaching and Learning (CTL). Teknik pengumpulan data yang akan dilakukan dalam penelitian ini adalah menggunakan metode tes.

Tes yang diberikan berupa Pre-Test dan PostTestdengan jumlah siswa masing-masing kelas adalah 32 siswa .Tes awal (pre-test) digunakan untuk memperoleh informasi tentang kemampuan awal siswa.Sedangkan tes akhir (post-test) digunakan untuk mengetahui ada tidaknya perbedaan kemampuan siswa setelah diberi perlakuan dan sebelum diberi perlakuan. Tes yang digunakan dalam penelitian ini adalah berupa tes subjektif (uraian) yang memuat 10 butir soal pada materi himpunan yang sudah diberikan kepada siswa. Siswa diberi waktu 2 JP (2x40 menit) dalam menyelesaikan soal tes baik soal pre-test maupun post test.

Sebelum peneliti memulai menganalisis data, peneliti harus mengolah data terlebih dahulu jika ingin hasil penelitian yang lebih baik. Untuk teknik-teknik tertentu, dalam mengolah data terlebih dahulu diperiksaapakah sudah memenuhi persyaratan atau belum. Persyaratan tersebut diantaranya, sampel harus berdistribusi normal. Di samping normal juga harus homogen.Teknik analisis data yang digunakan dalam penelitian ini menggunakan Uji Normalitas dan Uji Homogenitas (Arikunto,2013:357). Uji Normalitas data bertujuan untuk mengetahui apakah data tersebut berasal dari sampel yang berdistribusi normal atau tidak.Untuk menguji normalitas data yang diperoleh dari nilai tes pada materi yang diajarkan, dapat menggunakan uji Chi-Kuadrat.Setelah data dinyatakan berdistribusi normal, kemudian dilakukan Uji Homogenitas yang bertujuan untuk mengetahui apakah data bersifat homogen atau tidak. Setelah itu, dilakukan Uji Hipotesis.Untuk menguji hipotesis terdapat pengaruh pendekatan Contextual Teaching and Learning (CTL) terhadap hasil belajar matematika, didasarkan pada hasil analisis Uji-T. 


\section{HASILPENELITIAN}

Sehubungan dengan adanya persyaratan yang harus dipenuhi sebelum peneliti boleh menentukan teknik analisis yang digunakan, peneliti terlebih dahulu memeriksa keabsahan sampel untuk teknik tertentu, yaitu Uji Normalitas dan Uji Homogenitas. Hasil Uji Normalitas data pre-test kelas eksperimen dengan taraf signifikan 5\% dan derajat kebebasan $d k=5$ diperoleh $X_{\text {tabel }}^{2}=11,07$. Sedangkan hasil $X_{\text {hitung }}^{2}$ data pre-test kelas eksperimen diperoleh 2,55. Jika $X_{\text {hitung }}^{2}<X_{\text {tabel }}^{2}$ maka data berdistribusi normal.Dan sebaliknya, jika $X_{\text {hitung }}^{2} \geq X_{\text {tabel }}^{2}$ maka data berdistribusi tidak normal.Maka dapat disimpulkan bahwa data pre-test kelas eksperimen berdistribusi normal. Hasil Uji Normalitas data post-test siswa kelas ekperimen diperoleh $X_{\text {hitung }}^{2}=6,3$. Dengan demikian, dapat disimpulkan bahwa data post-test siswa kelas ekperimen berdistribusi normal. Sedangkan hasil Uji Normalitas pre-test kelas kontrol diperoleh $X_{\text {hitung }}^{2}=2,04$.Sehingga dapat disimpulkan bahwa data hasil pre-test siswa kelas kontrol berdistribusi normal. Hasil Uji Normalitas post-test kelas kontrol diperoleh $X_{\text {hitung }}^{2}=8,45$. Dapat disimpulkan bahwa data hasil posttest siswa kelas kontrol berdistribusi normal.

Setelah data dinyatakan berdistribusi normal,kemudian dilakukan Uji Homogenitas. Hasil Uji Homogenitas data pre-test diperoleh $F_{\text {hitung }}=1,14$ dan $F_{\text {tabel }}=1,82$ pada derajat kebebasan $d k_{1}=31$ dan $d k_{2}=31$ dengan taraf signifikan 5\%. Jika $F_{\text {Hitung }}<F_{\text {Tabel }}$ maka data tersebut bersifat homogen. Dan sebaliknya, jika $F_{\text {Hitung }} \geq F_{\text {Tabel }}$ maka data tersebut tidak homogen. Maka dapat disimpulkan bahwa pre-test hasilbelajar siswa bersifat homogen. Sedangkan hasil Uji Homogenitas data post-test diperoleh $F_{\text {Hitung }}=1,58$ dan $F_{\text {Tabel }}=1,82$ pada derajat kebebasan $d k_{1}=31 \quad$ dan $d k_{2}=31$ dengan taraf signifikan $5 \%$ yang berarti data tersebut bersifat homogen.
Setelah data dinyatakan normal dan homogen, kemudian peneliti melakukan pengujian hipotesis menggunakan rumus uji-t.Hipotesis yang digunakan adalah $\mathrm{H}_{\mathrm{o}}$ yaitu tidak ada pengaruh pendekatan Contextual Teaching and Learning (CTL) terhadap hasil belajar matematika siswa SMP Negeri 4 Waru dan $\mathrm{H}_{\mathrm{a}}$ yaitu ada pengaruh pendekatan Contextual Teaching and Learning (CTL) terhadap hasil belajar matematika siswa SMP Negeri 4 Waru. Analisis uji-takan diuraikan di bawah ini:

a. Mencari $t_{\text {hitung }}$ :

$$
\begin{aligned}
t & =\frac{\bar{x}_{1}-\bar{x}_{2}}{\sqrt{\frac{\left(n_{1}-1\right) s_{1}^{2}+\left(n_{2}-1\right) s_{2}^{2}}{n_{1}+n_{2}-2}\left(\frac{1}{n_{1}}+\frac{1}{n_{2}}\right)}} \\
& =\frac{90,729-86,188}{\sqrt{\frac{(31 \times 52,6)+(31 \times 82,9)}{32+32-2}\left(\frac{1}{32}+\frac{1}{32}\right)}} \\
& =\frac{4,541}{\sqrt{\frac{1630,6+2569,9}{62}\left(\frac{2}{32}\right)}} \\
& =\frac{4,541}{\sqrt{67,75\left(\frac{2}{32}\right)}} \\
& =\frac{4,541}{\sqrt{4,234}} \\
& =\frac{4,541}{2,057} \\
& =2,21
\end{aligned}
$$

b. Menentukan $t_{\text {tabel }}$ $\alpha=5 \%$

$d k=n_{1}+n_{2}-2$

$=32+32-2$

$=62$

Maka, $T_{\text {tabel }}=1,999$

c. Menentukan Kriteria Pengujian

Jika $T_{\text {Hitung }}<T_{\text {Tabel }}$ maka $H_{0}$ diterima

Jika $T_{\text {Hitung }}>T_{\text {Tabel }}$ maka $H_{a}$ diterima

d. Dari hasil di atas diperoleh $T_{\text {Tabel }}=1,999$ dan

$T_{\text {Hitung }}=2,21$. Sehingga dapat diketahui bahwa

$T_{\text {Hitung }}>T_{\text {Tabel }}=2,21>1,999$. 
e. Dapat diambil kesimpulan bahwa $\mathrm{H}_{\mathrm{a}}$ diterima. Artinya, terdapat pengaruh pembelajaran dengan pendekatan Contextual Teaching and Learning (CTL) terhadap hasil belajar matematika siswa SMP Negeri 4 Waru tahun ajaran 2015-2016.

\section{PEMBAHASAN}

Penelitian pengaruh pendekatan Contextual Teaching And Learning (CTL) terhadap hasil belajar matematika ini menghasilkan temuan yaitu ada pengaruh pendekatan Contextual Teaching and Learning (CTL) terhadap hasil belajar matematika SMP Negeri 4 Waru tahun ajaran 20152016. Hal tersebut dapat dicapai karena penelitian dilakukan dengan hati-hati dan teliti. Pelaksanaan penelitian ini dilakukan dalam dua kelas, yaitu kelas eksperimen dengan menggunakan pendekatan Contextual Teaching and Learning (CTL) yang dilakukan sebelum siswa mendapat perlakuan dan sesudah mendapat perlakuan, sedangkan kelas kontrol dengan menggunakan pembelajaran konvensional. Pre-test diberikan kepada kedua kelas untuk mengetahui kemampuan awal siswa sebelum menerima materi yang akan diajarkan.

Setelah proses pembelajaran selesai, kedua kelas diberi post-test. Hal ini bertujuan untuk mengetahui sejauh mana kemampuan siswa terhadap materi yang sudah diajarkan oleh peneliti.Dari hasil pre-test dan post-test siswa tersebut, kemudian peneliti menganalisis data hasil belajar siswa.Sebelum menguji hipotesis, peneliti melakukan uji normalitas dari data yang telah diperoleh.Uji normalitas dilakukan untuk mengetahui bahwa data yang dianalisis berdistribusi normal. Uji normalitas hasil pre-test siswa pada kelas kontrol diperoleh $2,04<11,07=T_{\text {Hitung }}<T_{\text {Tabel }}$ dan pada kelas eksperimen diperoleh $2,55<11,07=T_{\text {Hitung }}<T_{\text {Tabel }}$. Sedangkan hasil post-test pada kelas kontrol diperoleh $8,45<11,07=T_{\text {Hitung }}<T_{\text {Tabel }}$ dan pada kelas eksperimen diperoleh 6,3 $<11,07=T_{\text {Hitung }}<T_{\text {Tabel }}$. Setelah kedua kelas dinyatakan berdistribusi normal, maka dilakukan uji homogenitas. Uji homogenitas dilakukan untuk mengetahui bahwa kedua kelas yang akan dianalisis merupakan kelas yang homogen. Hasil pre-test kedua kelas diperoleh $1,14<1,82=T_{\text {Hitung }}<T_{\text {Tabel }}$ sedangkan hasil post-test kedua kelas diperoleh $1,58<1,82=T_{\text {Hitung }}<T_{\text {Tabel }}$. Maka, kedua kelas dinyatakan homogen.

Setelah data dinyatakan normal dan homogen, kemudian keduanya dilakukan uji hipotesis menggunakan uji-t. Diperoleh bahwa 2,21>1,999= $T_{\text {Hitung }}>T_{\text {Tabel }}$. Maka, dapat dinyatakan bahwa $H_{a}$ diterima. Artinya, ada pengaruh pendekatan Contextual Teaching and Leaning (CTL) terhadap hasil belajar matematika SMP Negeri 4 Waru tahun ajaran 2015-2016.

Pembelajaran Contextual Teaching and Learning (CTL) merupakan konsep belajar yang membantu guru mengaitkan antara materi yang diajarkan dengan situasi dunia nyata siswa dan mendorong siswa membuat hubungan antara pengetahuan yang dimilikinya dengan penerapannya dalam kehidupan mereka sebagai anggota keluarga dan masyarakat (Hasnawati, 2006:53). Pembelajaran dengan pendekatan CTL (Contextual Teaching and Learning) memiliki tujuh komponen utama (Trianto, 2012:193-195), yaitu:

1. Konstruktivisme,

2. Menemukan,

3. Bertanya,

4. Masyarakat Belajar,

5. Pemodelan,

6. Refleksi,

7. Penilaian yang sebenarnya.

Pendekatan Contextual Teaching and Learning (CTL) mempunyai pengaruh terhadap hasil belajar matematika siswa pada kelas eksperimen.Hasil penelitian ini membuktikan bahwa dengan menggunakan pendekatan Contextual Teaching and Learning (CTL) dapat meningkatkan hasil belajar matematika di SMP Negeri 4 Waru tahun ajaran 2015-2016.

\section{SIMPULAN}


Berdasarkan hasil analisis data yang telah dibahas sebelumnya, dapat disimpulkan bahwa ada pengaruh pendekatan Contextual Teaching and Learning (CTL) terhadap hasil belajar matematika SMP Negeri 4 Waru Tahun Ajaran 2015-2016.Kelas eksperimen yang diberikan perlakuan dengan menggunakan pendekatan Contextual Teaching and Learning (CTL) mempunyai rata-rata lebih tinggi dari pada kelas kontrol. Hal ini menunjukkan bahwa terdapat perbedaan hasil belajar antara siswa yang diberi perlakuan dengan pendekatan Contextual Teaching and Learning (CTL) dengan pembelajaran konvensional di kelas VII-6 dan VII-7 SMP Negeri 4 Waru.

\section{SARAN}

Berdasarkan hasil penelitian yang diperoleh, peneliti memberikan saran sebagai berikut:

a. Guru seharusnya menciptakan suasana yang menyenangkan dalam proses pembelajaran agar siswa tidak lagimenganggap matematika itu sulit dan membosankan,

b. Memberikan sarana dan prasarana yang memadai serta fasilitas yang mendukung dalam pelaksanaan kegiatan belajar mengajar, c. Sekolah dapat menyarankan kepada para pendidik untuk menggunakan pendekatan Contextual Teaching and Learning (CTL) dalam mata pelajaran yang lain.

\section{DAFTAR PUSTAKA}

Arikunto. 2013. Prosedur Penelitian: Suatu Pendekatan Praktik. Jakarta: Rineka Cipta.

Sudjana, Nana. 2011. Penilaian Hasil Proses Belajar Mengajar.Bandung: PT. Remaja Rosdakarya.

Sugiyono. 2013. Statistika Untuk Penelitian. Bandung: CV. Alfabeta.

Trianto. 2007. Model-model Pembelajaran Inovatif Berorientasi Konstruktivistik. Jakarta: Prestasi Pustaka.

Trianto. 2012. Mendesain Model Pembelajaran InovatifProgresif. Jakarta: Kencana.

Hasnawati. 2006. "Pendekatan Contextual Teaching Learning Hubungannya dengan Evaluasi Pembelajaran".Jurnal Ekonomi dan Pendidikan., Vol.3 No.1, pp. 53. 